\title{
Erratum to: The Use of Geographically Weighted Regression for Spatial Prediction: An Evaluation of Models Using Simulated Data Sets
}

\author{
P. Harris · A.S. Fotheringham • R. Crespo • \\ M. Charlton
}

Published online: 15 February 2011

(C) International Association for Mathematical Geosciences 2011

\section{Erratum to: Math Geosci (2010) 42: 657-680 \\ DOI 10.1007/s11004-010-9284-7}

This article has the following errors:

Section 3.1-in the last sentence of the second-to-last paragraph on p. 664

"Case 2 represents a fairly simple, non-stationary relationship between $z_{i}$ and $y_{i}$, whilst case 2 represents a more complex, non-stationary relationship."

should read

"Case 2 represents a fairly simple, non-stationary relationship between $z_{i}$ and $y_{i}$, whilst case $\mathbf{3}$ represents a more complex, non-stationary relationship."

Section 3.1-Fig. 1 on p. 665

Figs. 1C and 1D should be titled high heterogeneity rather than low heterogeneity.

The online version of the original article can be found under doi:10.1007/s11004-010-9284-7.

P. Harris $(\bowtie) \cdot$ A.S. Fotheringham $\cdot$ M. Charlton

National Centre for Geocomputation, National University of Ireland Maynooth, Maynooth,

Co. Kildare, Ireland

e-mail: Paul.Harris@nuim.ie

R. Crespo

Institute for Spatial and Landscape Planning, Swiss Federal Institute of Technology, Zurich, Switzerland 